\title{
Sonographic Assessment of the Normal Dimensions of Liver, Spleen, and Kidney in Healthy Children at Tertiary Care Hospital
}

\author{
Thapa NB, ${ }^{1}$ Shah $S,{ }^{2}$ Pradhan $A,{ }^{3}$ Rijal K, ${ }^{1}$ Pradhan $A,{ }^{1}$ Basnet $S^{4}$
}

\author{
${ }^{1}$ Department of Radiology \\ ${ }^{2}$ Department of Pediatrics \\ ${ }^{3}$ Department of Community Medicine \\ Kist Medical College Teaching Hospital, \\ Gwarko, Lalitpur, Nepal. \\ ${ }^{4}$ Department of Pediatrics \\ Institute of Medicine, \\ Maharajgunj, Kathmandu, Nepal. \\ Corresponding Author \\ Narayan Bikram Thapa \\ Department of Radiology, \\ Kist Medical College Teaching Hospital, \\ Gwarko, Lalitpur, Nepal. \\ E-mail-nadudocradio@yahoo.com
}

\section{Citation}

Thapa NB, Shah S, Pradhan A, Rijal K, Pradhan A, Basnet S. Sonographic Assessment of the Normal Dimensions of Liver, Spleen, and Kidney in Healthy Children at Tertiary Care Hospital. Kathmandu Univ Med J 2015;52(4):286-91.

\section{ABSTRACT}

\section{Background}

Ultrasonography is one of the most common imaging modality to measure dimensions of visceral organs in children. However, the normal limit of size of visceral organs according to age and body habitus has not been specified in the standard textbooks. This might result in under detection of organomegaly in pediatrics population.

\section{Objective}

The objective of this study was to determine the normal range of dimensions for the liver, spleen, and kidney in healthy children.

\section{Method}

This is prospective cross-sectional, hospital-based study done at Tertiary-care teaching hospital. Participants included 272 pediatric subjects ( 152 male and 120 female) with normal physical or sonographic findings who were examined because of problems unrelated to the measured organs. The subjects were one month to 15 year (180 months) old. All measured organs were sonographically normal. Relationships of the dimensions of these organs with sex, age, body weight and height were investigated. Limits of normal dimensions of these organs were defined.

\section{Result}

Normal length of liver, kidneys and spleen were obtained sonographically for 272 children (152 male [55.9\%] and 120 female [44.1\%]) in the age group from 1 months to 15 (180 months) years. The mean age was 45.78 months (SD, 44.73). The measured dimensions of all these organs showed highest correlation with height and age so the descriptive analysis of the organ dimensions (mean, minimum, and maximum values, SD and $5^{\text {th }}$ and $95^{\text {th }}$ percentiles) were expressed in 10 age groups along with height range of the included children. The mean length of right kidney was shorter than the left kidney length, and the difference was statistically significant $(p=0.001)$.

\section{Conclusion}

This study provides practical and comprehensive guide to the normal visceral organ dimension in pediatric population. The normal range limit of the liver, spleen, and kidney determined in this study could be used as a reference in daily practice in local radiology clinics.

\section{KEY WORDS}

Children, kidneys, liver, spleen, ultrasonography 


\section{INTRODUCTION}

Sonography is one of the most common imaging modality used in clinical practice. This is routinely used for evaluation of visceral organs in children because it is safe, quick and reliable for measuring the dimensions of visceral organs dimensions. This examination is real time, tridimensional, and independent of organ function. A large number of pathologic entities can affect size of the visceral organs, and the clinical examination might not be accurate to detect small increases in size. ${ }^{1}$ Liver and spleen size vary widely according to age. However, the normal limit of size of visceral organs according to age and body habitus has not been specified in the standard textbooks of radiology. Hence, the adult reference values are used most of the time that might lead to under detection of organomegaly in children. There are few studies to define the normal limits of organ dimensions in healthy children. However, available data are limited for the liver, spleen and kidney which causes difficulty in defining hepatomegaly, and splenomegaly on sonography. ${ }^{2-5}$ These data are even scarce among children of eastern world and Indian subcontinent where children are constitutionally small that might affect the organs size. Therefore, this study was conducted with the primary objective to determine the normal size of liver, spleen and kidney in healthy Nepalese children and to determine the relationship of each organ with sex, height and body weight. This study would also be helpful to establish our own standards. Thus, the study is believed to provide additional data to the literature on this subject.

\section{METHODS}

Children attending pediatrics outpatient department of KIST hospital for immunization, a follow-up examination for treated conditions, such as mild upper respiratory tract or urinary tract infections or who were examined because of problems unrelated to the above mentioned organs or a routine check-up were included in the study.

All the relevant medical records were checked by a pediatrician to ensure that selected children had no pathologic abnormalities (inflammatory, metabolic, congestive, traumatic, collagenous or hematologic diseases and malignancies) that could affect size of the measured organs. Sex, age, weight and height were determined for each child. Weight and height are noted to the nearest 0.1 $\mathrm{cm}$ with the use of a height scale and to the nearest 0.1 $\mathrm{kg}$ with the use of an electronic weighing scale. Severely underweight or overweight individuals or those with short or tall stature and small-for-date neonates, whose height (length) and weight are outside the corresponding ranges defined by the $5^{\text {th }}$ and $95^{\text {th }}$ percentiles of the WHO growth curves were excluded from the main analysis. Other clinical exclusion criteria included children with chronic renal failure, acute or chronic hepatitis, jaundice, fever, macular or maculopapular rash, and lymphadenopathy. Imaging exclusion criteria were parenchymal mass lesions, cysts, accessory spleens, hydronephrosis, and caliectasis.

The sonographic examinations were performed with a highresolution real-time scanner Siemens Acuson X 300 with a 3.6- $\mathrm{MHz}$ convex transducer. We used a $2.0-5.0 \mathrm{MHz}$ convex probe for the older children. Alternatively, we used a 5.010.0-MHz transducer for infants and younger children. The measurements of organ dimensions were made during deep inspiration. Liver measurements were performed in a supine position. The longitudinal axis was measured after clear visualization of the liver in the midclavicular plane. The uppermost edge under the dome of the diaphragm was defined as the upper margin, whereas the lowermost edge was defined as the lower margin. Spleen measurements are performed in a lateral decubitus position. Longitudinal size measurement of the spleen is performed between the most superomedial and the most inferolateral margins. The measurement of spleen length was the optimally maximum distance (ideally at the hilum) on the longitudinal coronal view (between the most superomedial and the most inferolateral points). Kidney measurements were performed in a lateral decubitus position. The renal hilum was visualized to get the optimum longitudinal dimension. All measurements of kidneys were made during quiet breathing in infants and younger children and in the older children, measurements were made while they were holding their breath. Three sequential measurements were taken and the mean was calculated; thus, we ensure minimum intra operator variation and greater accuracy and reliability of measurements.

The study was carried out after approval by the scientific board of the hospital, and parents' informed consent was obtained for all selected children.

\section{RESULTS}

Two hundred and seventy two children (152 male [55.9\%] and 120 female [44.1\%]) in the age group from 1 months to 15 (180 months) years were enrolled in the study. The mean age was 45.78 months (SD, 44.73), and median was 26 months. There was no statistically significant difference between the two sexes in any age group for the organ dimensions ( $t$ test, $p>0.05$ ). Therefore, all data were rearranged without being separated according to sex. The longitudinal dimensions of each organ showed highest correlation with the body parameters (i.e. age, height, and weight). Among these variables also the correlation coefficients (Pearson $r$ ) was highly correlated with height and age for all the measured organs. The correlation coefficients for height for liver, spleen, right kidney and left kidney were $0.81,0.76,0.83$, and 0.89 , respectively (Tables 1). Hence, the normal values for each of these organs are also expressed in 10 age groups and height range. As both visceral organs growth and physical growth occurs at rapid rate in initial few years of human life. Therefore, the results 
Table 1. Correlation coefficients of organ dimensions with weight, height, and age.

\begin{tabular}{lllll}
\hline Body parameter & Liver & Spleen & Right kidney & Left kidney \\
\hline Height & 0.81 & 0.76 & 0.83 & 0.89 \\
\hline Weight & 0.74 & 0.67 & 0.71 & 0.78 \\
\hline Age & 0.78 & 0.74 & 0.82 & 0.88 \\
\hline
\end{tabular}

of the present study with the measured dimension of the organs are segregated into four groups till two years and in wider age intervals in the subsequent years.

The descriptive analysis of the organ dimensions (mean, minimum, and maximum values, SD and $5^{\text {th }}$ and $95^{\text {th }}$ percentiles) are shown in Tables 2-5. The mean length of right kidney was shorter than the left kidney length, and the difference was statistically significant $(p=0.001)$. The children were separated into 10 groups according to their age and the $5^{\text {th }}$ and $95^{\text {th }}$ percentiles were made for each group.

Table 2. Splenic length in healthy children with normal somatometric parameters from 1 month to 15 years according to age group and height range.

\begin{tabular}{|c|c|c|c|c|c|c|c|c|c|}
\hline \multirow[t]{2}{*}{ Age in months } & \multirow[t]{2}{*}{ No. of children } & \multicolumn{5}{|c|}{ Spleen length $(\mathrm{cm})$} & \multicolumn{2}{|c|}{ Percentile } & \multirow{2}{*}{$\begin{array}{l}\text { Body heigh } \\
\text { range }(\mathrm{cm})\end{array}$} \\
\hline & & Mean & SD & Median & Minimum & Maximum & $5^{\text {th }}$ & $95^{\text {th }}$ & \\
\hline $1-6$ & 36 & 5.075 & 0.79 & 5.1 & 3.1 & 7.6 & 3.61 & 6.24 & $50-76$ \\
\hline $7-12$ & 35 & 6.008 & 0.79 & 6 & 3.6 & 7.9 & 4.72 & 7.58 & $61.6-89$ \\
\hline $13-18$ & 39 & 6.02 & 0.74 & 6.1 & 4.7 & 7.7 & 4.7 & 7.2 & $65.5-87$ \\
\hline $19-24$ & 23 & 6.25 & 0.89 & 6.2 & 5 & 8.2 & 5.06 & 8.16 & $75-89$ \\
\hline $25-48$ & 43 & 6.81 & 0.92 & 6.8 & 5 & 9.2 & 5.42 & 8.16 & $82.2-104$ \\
\hline $49-72$ & 28 & 6.93 & 0.70 & 7 & 5.5 & 8.2 & 5.54 & 8.06 & 73-116 \\
\hline $73-84$ & 13 & 7.65 & 0.85 & 7.7 & 6.7 & 9 & 6.7 & 9 & $100-126.5$ \\
\hline $85-120$ & 25 & 7.59 & 0.84 & 7.9 & 5.9 & 9.2 & 5.93 & 9.05 & 101-139 \\
\hline $121-144$ & 19 & 8.17 & 1.07 & 8 & 6.3 & 10.4 & 6.3 & 11 & $112-150$ \\
\hline $145-180$ & 11 & 8.91 & 0.97 & 8.8 & 7.4 & 10.3 & 7.4 & 10.3 & $136-161$ \\
\hline
\end{tabular}

Table 3. Hepatic length in healthy children with normal somatometric parameters from 1 month to 15 years according to age group and height range.

\begin{tabular}{|c|c|c|c|c|c|c|c|c|c|}
\hline \multirow[t]{2}{*}{ Age in months } & \multirow[t]{2}{*}{ No. of children } & \multicolumn{5}{|c|}{ Liver length (cm) } & \multicolumn{2}{|c|}{ Percentile } & \multirow{2}{*}{$\begin{array}{l}\text { Body height } \\
\text { range }(\mathrm{cm})\end{array}$} \\
\hline & & Mean & SD & Median & Minimum & Maximum & $5^{\text {th }}$ & $95^{\text {th }}$ & \\
\hline $1-6$ & 36 & 6.88 & 0.70 & 6.95 & 5.4 & 8.2 & 5.49 & 8.03 & $50-76$ \\
\hline $7-12$ & 35 & 7.65 & 0.93 & 7.5 & 5.9 & 9.2 & 4.72 & 7.58 & $61.6-89$ \\
\hline $13-18$ & 39 & 8.35 & 0.62 & 8.4 & 7 & 9.6 & 7.1 & 9.3 & $65.5-87$ \\
\hline $19-24$ & 23 & 8.50 & 0.85 & 8.4 & 6.7 & 9.6 & 6.82 & 9.6 & $75-89$ \\
\hline $25-48$ & 43 & 8.73 & 0.89 & 8.7 & 7.2 & 10.8 & 7.34 & 10.52 & $82.2-104$ \\
\hline $49-72$ & 28 & 9.12 & 0.83 & 9.2 & 7.6 & 11 & 7.65 & 10.91 & $73-116$ \\
\hline $73-84$ & 13 & 9.31 & 0.99 & 9.2 & 7.4 & 10.4 & 7.4 & 10.4 & $100-126.5$ \\
\hline $85-120$ & 25 & 9.87 & 0.87 & 9.7 & 8.4 & 12 & 8.46 & 11.76 & $101-139$ \\
\hline $121-144$ & 19 & 10.63 & 1.07 & 10.4 & 9.2 & 12.7 & 9.2 & 12.7 & $112-150$ \\
\hline $145-180$ & 11 & 11.61 & 0.88 & 11.8 & 10.4 & 13 & 10.4 & 13 & $136-161$ \\
\hline
\end{tabular}


Table 4. Right renal length in healthy children with normal somatometric parameters from 1 month to 15 years according to age group and height range

\begin{tabular}{|c|c|c|c|c|c|c|c|c|c|}
\hline \multirow[t]{2}{*}{ Age in months } & \multirow[t]{2}{*}{ No. of children } & \multicolumn{5}{|c|}{ Right renal length $(\mathrm{cm})$} & \multicolumn{2}{|c|}{ Percentile } & \multirow{2}{*}{$\begin{array}{l}\text { Body height } \\
\text { range }(\mathrm{cm})\end{array}$} \\
\hline & & Mean & SD & Median & Minimum & Maximum & $5^{\text {th }}$ & $95^{\text {th }}$ & \\
\hline $1-6$ & 36 & 4.86 & 0.48 & 4.9 & 4 & 6 & 4.09 & 6 & $50-76$ \\
\hline $7-12$ & 35 & 5.42 & 0.64 & 5.3 & 4 & 7.7 & 4.48 & 6.82 & 61.6-89 \\
\hline $13-18$ & 39 & 5.51 & 0.51 & 5.4 & 4.2 & 6.7 & 4.9 & 6.4 & $65.5-87$ \\
\hline $19-24$ & 23 & 5.75 & 0.49 & 5.6 & 4.9 & 7 & 4.92 & 6.94 & $75-89$ \\
\hline $25-48$ & 43 & 6.3 & 0.68 & 6.4 & 4.8 & 7.6 & 5.2 & 7.4 & $82.2-104$ \\
\hline 49-72 & 28 & 6.98 & 0.56 & 6.95 & 6 & 8.1 & 6 & 8.01 & 73-116 \\
\hline $73-84$ & 13 & 7.55 & 0.52 & 7.6 & 6.4 & 8.2 & 6.4 & 8.2 & $100-126.5$ \\
\hline $85-120$ & 25 & 7.49 & 0.72 & 7.4 & 6 & 8.8 & 6.15 & 8.71 & 101-139 \\
\hline $121-144$ & 19 & 8.34 & 0.72 & 8.3 & 6.8 & 9.5 & 6.8 & 9.5 & $112-150$ \\
\hline $145-180$ & 11 & 9.15 & 0.53 & 9.3 & 8.2 & 9.7 & 8.2 & 9.7 & $136-161$ \\
\hline
\end{tabular}

Table 5. Left renal length in healthy children with normal somatometric parameters from 1 month to 15 years according to age group and height range

\begin{tabular}{|c|c|c|c|c|c|c|c|c|c|}
\hline \multirow[t]{2}{*}{ Age in months } & \multirow[t]{2}{*}{ No. of children } & \multicolumn{5}{|c|}{ Left renal length $(\mathrm{cm})$} & \multicolumn{2}{|c|}{ Percentile } & \multirow{2}{*}{$\begin{array}{l}\text { Body height } \\
\text { range }(\mathrm{cm})\end{array}$} \\
\hline & & Mean & SD & Median & Minimum & Maximum & $5^{\text {th }}$ & $95^{\text {th }}$ & \\
\hline $1-6$ & 36 & 5.03 & 0.50 & 4.95 & 4 & 6 & 4.17 & 5.91 & $50-76$ \\
\hline $7-12$ & 35 & 5.58 & 0.52 & 5.6 & 4.7 & 7.2 & 4.86 & 6.72 & $61.6-89$ \\
\hline $13-18$ & 39 & 5.85 & 0.48 & 5.8 & 5.1 & 7.3 & 5.1 & 6.6 & $65.5-87$ \\
\hline $19-24$ & 23 & 5.99 & 0.59 & 5.9 & 5.1 & 6.9 & 5.1 & 6.9 & $75-89$ \\
\hline $25-48$ & 43 & 6.64 & 0.80 & 6.5 & 5 & 8.6 & 5.38 & 8.14 & $82.2-104$ \\
\hline $49-72$ & 28 & 7.12 & 0.58 & 7.1 & 6.3 & 8.4 & 6.3 & 8.31 & $73-116$ \\
\hline $73-84$ & 13 & 7.72 & 0.53 & 7.7 & 6.6 & 8.7 & 6.6 & 8.7 & $100-126.5$ \\
\hline $85-120$ & 25 & 7.7 & 0.74 & 7.7 & 6.3 & 9 & 6.36 & 9 & 101-139 \\
\hline $121-144$ & 19 & 8.56 & 0.62 & 8.6 & 7.4 & 9.8 & 7.4 & 9.8 & $112-150$ \\
\hline $145-180$ & 11 & 9.4 & 0.62 & 9.4 & 8.6 & 10.5 & 8.6 & 10.5 & $136-161$ \\
\hline
\end{tabular}

\section{DISCUSSION}

I In the literature, there are few detailed studies to interpret the organ dimensions by ultrasound in children. ${ }^{2-19}$ Our objective in this study was to define the normal limits of organ dimensions for Nepalese children. To the best of our knowledge, our study, which aimed to investigate the normal limits of the liver, spleen, and kidneys, is the first series in the literature to determine the normal limits of organ dimensions among Nepalese children.

We did not find any significant difference in size of organs between the two sexes in any age group (t test, $p>0.05$ ). Therefore, the results of the present study are not expressed according to sex. Previous studies done by Christophe, Han, Dremshek also did not find any significant difference in organ sizes between two sexes. ${ }^{7-9}$ This indicates that sex does not influence on the size of the organ. However, the difference in size of organs between the two sexes needs to be confirmed in larger pediatrics population.

We found that height and age show the best correlation with any one of the mentioned organ dimensions. Weight also shows a correlation with organ dimensions, but to a lesser degree. However, its derivation is not as practical as height. For this reason, we preferred to use height and age 
ranges in standard tables. Therefore, while deciding the normal sonographic dimensions of an organ, patient height should be the primary concern.

Among the previous studies, Rosenberg et al. and Megremis et al. have provided ultrasonographic data on spleen size in 230 and 512 children, respectively. ${ }^{2,11}$ Among the studies providing normative data on both liver and spleen size, Safak et al. studied 712 children between 7-15 year old and provided data according to body weight groups. ${ }^{14}$ Konus et al. studied liver and spleen sizes for 307 children and provided the data in height-range and age-groups. ${ }^{20}$ When we compared the median organ lengths according to age group, our findings roughly seemed to agree with theirs. The findings of various similar studies differ somewhat from each other and from our. The organ dimensions of present study are larger than those of Holder et al. ${ }^{15}$ The reason is probably that they used linear transducers and performed the measurements in a sagittal plane passing through the midpoint of the right and left margins of liver. Linear transducers because of the interposition of lung between the dome of the liver and the anterior abdominal wall, observes some of the superior portion of the liver at times.

As the midclavicular line is known to vary widely when evaluated by different observers, we pre-determined it for the sonographic assessments, thus, consistency of measurement was ensured. Nutritional anemia, chronic systemic illnesses and malnutrition may be associated with organomegaly so all children were thoroughly examined by pediatrician and were specifically excluded if any of the above conditions were identified. There are however some limitations of our study. The number of subjects in the age group 73-84 months and 145-180 months were less. Although, many previous studies have published normative data using similar small numbers, the small sample size in certain groups may affect the generalization of the values to these age-groups. In most other studies, sizes between the fifth and the 95th percentile were the accepted normal limits..$^{6,710,15,16}$ Hence, cutoff values at $5^{\text {th }}$ and $95^{\text {th }}$ percentile were considered in the present study. However, this practice might results in approximately $10 \%$ of children with normal visceral organ sizes falling outside this limits. ${ }^{19}$

Nevertheless, by presenting the largest pediatric series so far, we tried to provide a more accurate assessment of liver and spleen sizes in children, especially those in Nepal.

\section{CONCLUSION}

Body height should be considered as the best criteria to correlate with longitudinal dimensions of these organs. However, the organ dimension is not different in two sexes. This study provides practical and comprehensive guide to the normal visceral organ dimension in pediatric population. The normal range limit of the liver, spleen, and kidney determined in this study could be used as a reference in daily practice in local radiology clinics.

\section{ACKNOWLEDGEMENT}

IRB Kist medical college for the permission and logistic support to conduct and publish the study.

\section{Contributors:}

SB conceptualized the study, collated the results, conducted the literature search and drafted the manuscript. SS was involved in patient selection, enrolment and clinical data collection. AP and KP conducted the sonographic evaluation. AP conducted the statistical analysis, and reviewed the manuscript for important intellectual content. All the authors were involved in the approval of the final manuscript to be published.

\section{REFERENCES}

1. Zhang B, Lewis SM. A study of the reliability of clinical palpation of the spleen. Clin Lab Haematol 1989;11:7-10.

2. Rosenberg HK, Markowitz RI, Kolberg H, Park C, Hubbard A, Bellah RD. Normal splenic size in infants and children: sonographic measurements. AJR Am J Roentgenol 1991;157:119-21.

3. Oznur L. Konus, Aysegul, Ozdemir, AlaaddiAnkkaya. Normal Liver, Spleen, and Kidney Dimensions in Neonates, Infants,and Children: Evaluation with Sonography. AJR 1998;171;1693-8

4. Stylianos D. Megremis, loannis G. Vlachonikolis, Amalia M. Tsilimigaki. Spleen Length in Childhood with US: Normal Values Based on Age, Sex, and Somatometric Parameters. Radiology 2004;231:129-34

5. Alp Alper Safak, Enver Simsek, Talat Bahcebasi. Sonographic Assessment of the Normal Limits and Percentile Curves of Liver, Spleen, and Kidney Dimensions in Healthy School-Aged Children. J Ultrasound Med 2005; 24:1359-64

6. Dittrich M, Milde S. Dinkel E, Baumann W, Weitzel D. Sonographic biometry of liver and spleen size in childhood. Pediatr Radiol 1983;13: 206.

7. Christophe C, Cantraine F, Bogaert. Ultrasound: a method for kidney size monitoringinchildren. EurJ Pediatr 1986;145:532-8.

8. Han BK, Babcock DS. Sonographic measurements and appearance of normal kidneys in children. AJR 1985;145:611.

9. Dremsek PA, Kritscher H, Bohm G, Hochberger O. Kidney dimensions in ultrasound compared to somatometric parameters in normal children. Pediatr Radiol 1987;17:285-90.

10. Rosenbaum DM, Korngold E, Teele RL. Sonographic assessment of renal length in normal children. AJR 1984;142:467-9.

11. Megremis SD, Vlachonikolis LG, Tsilimigaki AM. Spleen length in childhood with US: Normal values based on age, sex and somatometric parameters. Radiology 2004; 23:129-34. 
12. Chen $\mathrm{CM}$, Wang JJ. Clinical and sonographic assessment of liver size in normal Chinese neonates. Acta Paediatr 1993; 82:345-7.

13. Singh K, Bhasin DK, Reddy DN, Koshy A. Liver span in normal Indians. Indian J Gastroenterol 1985; 4: 73-5.

14. Safak AA, Simsek E, Bahcebasi T. Sonographic assessment of the normal limits and percentile curves of liver, spleen, and kidney dimensions in healthy school-aged children. J Ultrasound Med 2005; 24: 1359-64.

15. Holder L, Strife J, Padikal TN, Perkins PJ, Ker elakesJG. Liver size determination in pediatrics using sonographic and scintigraphic techniques. Radiology 1975;17:349-53.
16. Han BK, Babcock DS. Sonographic measurements and appearance of normal kidneys in children. AJR 1985;145:611.

17. Elakes JG. Liver size determination in pediatrics using sonographic and scintigraphic techniques. Radiology 1975;17:349-53.

18. Markisz JA, TrevesST.Davis RT Normal hepatic and splenic size in children: scintigraphic determination. Pediatr Radiol 1987;17:273-6.

19. Zerin JM, Blanc CE. Sonographic assessment of renal length in children: a reappraisal. Pediatr Radiol 1994;24:101-6.

20. Konus OL, Ozdemir A, Akkaya A, Erbas G, Celik H, Isik S. Normal liver, spleen and kidney dimensions in neonates, infants and children: evaluation with sonography. AJR Am J Roentgenol 1998; 171:1693-8. 